\title{
Understanding individual variation in levels of second language attainment through the lens of critical period mechanisms
}

\author{
REBECCA REH \\ Department of Psychology, University of British Columbia \\ MARIA ARREDONDO \\ Department of Psychology, University of British Columbia \\ JANET F. WERKER \\ Department of Psychology, University of British Columbia
}

(Received: January 27, 2018; accepted: January 28, 2018; first published online 13 June 2018)

Mayberry and Kluender (2017) present an important and compelling argument that in order to understand critical periods (CPs) in language acquisition, it is essential to disentangle studies of late first language (L1) acquisition from those of second language (L2) acquisition. Their primary thesis is that timely exposure to an L1 is crucial for establishing language circuitry, thus providing a foundation on which an L2 can build. They note that while there is considerable evidence of interference from the L1 on acquisition of the L2 - especially in late L2 learners (as in our work on cascading influences on phonetic category learning and visual language discrimination, e.g., Werker \& Hensch, 2015 and Weikum, Vouloumanos, Navarra, Soto-Faraco, Sebastián-Gallés \& Werker, 2013, respectively) - there are other examples of ways in which the L1 can scaffold L2 acquisition. Mayberry and Kluender take this evidence of L1 scaffolding L2 as undermining the value of considering CPs as useful in understanding L2 acquisition.

It is undoubtedly the case that the L1 scaffolds acquisition of the L2. This is seen in phonetic perception, wherein L2 learners use the properties of the L1 to guide the establishment of new phonetic categories - with evidence of scaffolding, but also interference (SebastiánGallés \& Kroll, 2003). It is evident, as well, in studies that have investigated the circuitry and neural responses underlying L2 processing. For example, a recent fNIRS study, using grammatical judgments to compare morphosyntactic processing of proficient bilingual children (L2 learners before age 5) to monolingual children of the same age, found hemodynamic activity over cortical frontal regions in the two samples, as well as across the two languages for the bilinguals. Importantly, the activation patterns were stronger and more restricted to the left inferior frontal gyrus (a region underlying the language network) for the bilinguals than for the monolinguals, consistent with the claim that the L1 provides a foundation for $\mathrm{L} 2$ acquisition (Arredondo, $\mathrm{Hu}$, Seifert, Satterfield \& Kovelman, under revision). In both phonetic and morphosyntactic processing, however, there are increases in variability in performance and underlying neural activation as the age of acquisition increases, with many if not most adults failing to attain nativelike levels of proficiency (Pallier, Bosch \& SebastiánGallés, 1997 for phonetic discrimination; McLaughlin, Tanner, Pitkänen, Frenck-Mestre, Inoue, Valentine \& Osterhout, 2010 for morphosyntactic processing). Indeed, different pathways are involved in late L2 as opposed to L1 learners; in particular, there is greater frontal lobe involvement (Myers, 2014, for phonetic discrimination; Finn, Kam, Ettlinger, Vytlacil \& D'Esposito, 2013, for morphosyntax). Moreover, the brain matures in a posterior-to-anterior manner, and the frontal lobe is not fully mature until the mid-twenties (Gogtay, Giedd, Lusk, Hayashi, Greenstein, Vaituzis, Nugent, Herman, Clasen, Toga, Rapoport \& Thompson, 2004). Levels of motivation for acquiring an L2 can vary by age and social contexts, where 'fitting in with peers' is important during some developmental periods (i.e., puberty and early adulthood). Perhaps these later-developing frontal areas play a more important role in L2 acquisition, particularly late L2 acquisition, and if so, this frontal modulation may play a role in modulating $\mathrm{CP}$ plasticity.

Thus, rather than taking the variability in level of attainment in late L2 learners as evidence against CPs, we suggest that a mechanistic understanding of how CPs operate can illuminate why some late L2 learners attain high levels of competency - even for very fundamental aspects of language processing, such as phonology and morphology - and others do not.

Mayberry and Kluender imply that because there is no animal model for language acquisition, the elucidation of neuronal mechanisms underlying $\mathrm{CP}$ plasticity in different species is not relevant. We argue, however, that

Address for correspondence:

Department of Psychology, University of British Columbia, 2136 West Mall, Vancouver, BC, Canada, V6T 1Z4

jwerker@psych.ubc.ca 
because these mechanisms are conserved across species and systems, understanding them may help inform why a limited number of L2 learners successfully acquire native levels of proficiency later in life (Werker \& Hensch, 2015). The plasticity versus stability of cortical circuits is constrained by a number of brake-like factors, including factors which act through neuromodulatory systems. For example, plasticity is inhibited by both Lynx 1 (which dampens binding to acetylcholine receptors) and serotonin reuptake (Morishita, Miwa, Heintz, \& Hensch, 2010; Maya Vetencourt, Sale, Viegi, Baroncelli, De Pasquale, O'Leary, Castrén \& Maffei, 2008). The level of these brake-like factors can influence the duration and closure of $\mathrm{CPs}$, as well as re-open them later in life. In particular, Mayberry and Kluender cite motivation as a key factor in L2 success. The serotonergic system plays a role in regulating motivation behavior (Correia, Lottem, Banerjee, Machado, Carey \& Mainen, 2017), and exposure to SSRIs alters CPs in both rodents and humans (Maya Vetencourt et al., 2008; Weikum, Oberlander, Hensch \& Werker, 2012). Arousal, acting through the cholinergic system, also opens CP plasticity (Stryker, 2014). Top-down attentional processes activate the cholinergic system, both through the basal forebrain and possibly through direct corticocortical projections, providing an additional pathway through which motivation may boost plasticity (Hasselmo \& Sarter, 2011). Thus, motivation may tap into similar mechanisms that regulate L1 acquisition from childhood.

In conclusion, Mayberry and Kluender's important insight provides much-needed theoretical clarification to the understanding of the role CPs play in L1 versus L2 acquisition. We argue, nonetheless, that the importance CPs may play in L2 acquisition should not be ignored. Turning to a mechanistic understanding of how CPs operate, including a consideration of how frontally mediated cognitive processes such as attention and arousal can modulate $\mathrm{CP}$ circuits, may better illuminate understanding of individual variability in L2 attainment.

\section{References}

Arredondo, M. M., Hu, X., Seifert, E., Satterfield, T., \& Kovelman, I. (under revision). Bilingual exposure enhances left IFG specialization for language in children. Bilingualism: Language \& Cognition.

Correia, P. A., Lottem, E., Banerjee, D., Machado, A. S., Carey, M. R., \& Mainen, Z. F. (2017). Transient inhibition and long-term facilitation of locomotion by phasic optogenetic activation of serotonin neurons. eLife, 6, e20975. doi: 10.7554/eLife. 20975

Finn, A. S., Kam, C. L. H., Ettlinger, M., Vytlacil, J., \& D'Esposito, M. (2013). Learning language with the wrong neural scaffolding: the cost of neural commitment to sounds. Frontiers in Systems Neuroscience, 7. doi: 10.3389/fnsys. 2013.00085
Gogtay, N., Giedd, J. N., Lusk, L., Hayashi, K. M., Greenstein, D., Vaituzis, A. C., Nugent, T. F. 3rd, Herman, D. H., Clasen, L. S., Toga, A. W., Rapoport, J. L., \& Thompson, P. M. (2004). Dynamic mapping of human cortical development during childhood through early adulthood. Proceedings of the National Academy of Sciences of the United States of America, 101, 8174-8179. doi: 10.1073/pnas.0402680101

Hasselmo, M. E., \& Sarter, M. (2011). Modes and models of forebrain cholinergic neuromodulation of cognition. Neuropsychopharmacology, 36, 52-73. doi:10.1038/npp.2010.104

Maya Vetencourt, J. F., Sale, A., Viegi, A., Baroncelli, L., De Pasquale, R., O’Leary, O. F., Castrén, E., \& Maffei, L. (2008). The antidepressant fluoxetine restores plasticity in the adult visual cortex. Science, 320, 385-388. doi:10.1126/science. 1150516

Mayberry, R. I., \& Kluender, R. (2017). Rethinking the critical period for language: New insights into an old question from American Sign Language. Bilingualism: Language and Cognition doi:10.1017/S13667289170007

McLaughlin, J., Tanner, D., Pitkänen, I., Frenck-Mestre, C., Inoue, K., Valentine, G., \& Osterhout, L. (2010). Brain potentials reveal discrete stages of L2 grammatical learning. Language Learning, 60, 123-150. doi:10.1111/j.1467-9922.2010.00604.x

Morishita, H., Miwa, J. M., Heintz, N., \& Hensch, T. K. (2010). Lynx1, a cholinergic brake, limits plasticity in adult visual cortex. Science, 330, 1238-1240. doi: $10.1126 /$ science. 1195320

Myers, E. B. (2014). Emergence of category-level sensitivities in non-native speech sound learning. Frontiers in Neuroscience, 8. doi:10.3389/fnins.2014.00238

Pallier, C., Bosch, L., \& Sebastián-Gallés, N. (1997). A limit on behavioral plasticity in speech perception. Cognition, 64, B9-B17. doi:10.1016/S0010-0277(97)00030-9

Sebastián-Gallés, N., \& Kroll, J. (2003) Phonology in bilingual language Processing: Acquisition, Perception, and Production. In N. O. Schiller and A. Meyer (Eds.), Phonetics and Phonology in Language Comprehension and Production: Differences and Similarities (pp. 279-318). Berlin: Mouton de Gruyter.

Stryker, M. P. (2014). A neural circuit that controls cortical state, plasticity, and the gain of sensory responses in mouse. Cold Spring Harbor Symposia on Quantitative Biology, 79, 1-9. doi: $10.1101 /$ sqb.2014.79.024927

Weikum, W. M., Oberlander, T. F., Hensch, T. K., \& Werker, J. F. (2012). Prenatal exposure to antidepressants and depressed maternal mood alter trajectory of infant speech perception. Proceedings of the National Academy of Sciences, 109, 17221-17227. doi: 10.1073/pnas.1121263109

Weikum, W.M., Vouloumanos, A., Navarra, J., Soto-Faraco, S., Sebastián-Gallés, N., \& Werker, J.F. (2013). Age-related sensitive periods influence visual language discrimination in adults. Frontiers in Systems Neuroscience, 7, 86.

Werker, J. F., \& Hensch, T. K. (2015). Critical Periods in Speech Perception: New Directions. Annual Review of Psychology, 66. doi:10.1146/annurev-psych-010814015104 